\title{
Purification and Identification of Angiotensin I-Converting Enzyme Inhibitor from Morokheiya (Corchorus olitorius)
} \author{
Yasuo AOY AGI ${ }^{3}$ \\ ${ }^{1}$ Nutritional Biochemistry, Tokyo Kasei University, Itabashi-ku, Tokyo 173, Japan \\ ${ }^{2}$ Food and Nutritional Chemistry, Kinki University, Nakamati, Nara 631, Japan \\ ${ }^{3}$ Food Chemistry, Women's College of Nutrition, Toshima-ku, Tokyo 170, Japan
}

Koichi Kimoto, ${ }^{1}$ Yuko Kuroda,,${ }^{1}$ Yumiko Saito, ${ }^{1}$ Junko Yamamoto, ${ }^{1}$ Tetsuo Murakami ${ }^{2}$ and

Received November 10, 1996; Accepted March 3, 1998

\begin{abstract}
In order to invesigate another function such as food in Morokheiya, the angiotensin-converting enzyme (ACE) inhibitor was extracted with $\mathbf{8 0 \%}$ ethanol from the leaves of Morokheiya (Corchorus olitorious). The extract was dried, dissolved in water, defatted with ether and decolored with activated carbon. The ACE inhibitor was purified by successive ion-exchange chromatography, Amberlite IR-120B, Dowex 50W-X8 and Dowex 1-X4, respectively. The ACE inhibitor was further purified by silica gel column chromatography and finally purified and isolated by high performance liquid chromatography (HPLC) on Asahipak NH2P-50. The ACE inhibitor showed a positive ninhydrin reaction and no significant absorbance. The present $\mathrm{ACE}$ inhibitor was identified as Nicotianamine based on the comparative study using amino acid analyzer, TLC and capillary electrophoresis.
\end{abstract}

Keywords: ACE inhibitor, amino acid, nikotianamine

Life-style related diseases, such as obesity, diabetes mellitus, hypertension and cardiovascular disease, have been recently increasing. In each population, deaths due to heart disease or vascular disease have been the number 2 and 3 killers. However, their total is greater than that of the number 1 cause of death, cancer. Especially, hypertension is a most important disease because it may induce cerebral apoplexy and cardiovascular disease, moreover, obesity can cause hypertension. Over $90 \%$ of the hypertension cases is called essential hypertension. About $2 / 3$ of the essential hypertension is related to renin-angiotensin systems (RA system). This system is well understood (Dzau, 1988) as follows: renin from the kidney hydrolyzes angiotensinogen, the prehormone of the hypertensive peptide, from the liver. Angiotensin I is produced and converted to angiotensin II, a hypertensive peptide, by the angiotensin-converting enzyme (ACE). ACE participates in the control of blood pressure, and its inhibitors such as captoprile and enalaprile have been used as antihypertensive drugs. In recent years, a number of ACE inhibitors have been isolated from various food protein sources (Murayama \& Suzuki, 1982; Kohama et al., 1988; Ukeda et al., 1991), and some of them have an effect on the decrease in blood pressure of spontaneously hypertensive rats (SHR). Morokheiya is a well-known vegetable which contains high nutritional components and is speculated to have good effects on health. We found ACE inhibitory activity in the extract from Morokheiya. In this paper, we present the isolation and identification of the ACE inhibitor from Morokheiya leaves.

Materials Morokheiya was obtained from the Hanyuu Agricultural Corp., Saitama Prefecture. ACE was purchased from the Sigma Chemical Co. (St. Louis, MO). Hip-his-leu was from the Peptide Institute (Osaka). The TLC plate (silica gel $60 \mathrm{~F}_{254}$ ) was obtained from the Merck Co. (Frankfurter, Germany). Other chemicals were purchased from Wako Pure Chemicals (Osaka).

Assay for ACE inhibitory activity ACE inhibitory activity was assayed by a modification of the method of Cushman and Cheung (1971). The reaction mixture contained $500 \mu \mathrm{l}$ of $7 \mathrm{~mm}$ hip-his-leu in $200 \mathrm{mM}$ of borate buffer, $\mathrm{pH} 8.3,400 \mu \mathrm{l}$ of $2 \mathrm{M} \mathrm{NaCl}, 40 \mu \mathrm{l}$ of distilled water and $30 \mu \mathrm{l}$ of inhibitor sample or $\mathrm{H}_{2} \mathrm{O}$. After $30 \mathrm{~min}$ at $37^{\circ} \mathrm{C}$, the reaction was stopped by adding $500 \mu \mathrm{l}$ of $1 \mathrm{~N} \mathrm{HCl}$, and the hippuric acid was extracted with ethylacetate. A $2.0 \mathrm{ml}$ aliquot of the extract was evaporated to dryness and the residue was dissolved in $1.0 \mathrm{ml}$ of $\mathrm{H}_{2} \mathrm{O}$. The hippuric acid concentration was determined from the absorbance at $228 \mathrm{~nm}$. Inhibitory activity was calculated as follows: Residual activity $=$ (sampleblank $) /($ control-blank $) \times 100$, Inhibitory activity $=100$-residual activity.

Purification of ACE inhibitor For the first step, $80 \%$ ethanol was used as the extraction solvent because an aqueous solvent was jellied by the Morokheiya contents. The extract was treated by activated carbon for decoloration and ether for defatting. ACE inhibitory activity was separated with Amberlite IR-120B. The ACE inhibitor was applied to the Dowex 1-X4 column $(32 \phi \times 835 \mathrm{~mm})$ previously activated as the acetate type. The active fractions were collected, evaporated to dryness and dissolved in a pyridine-acetate mixture, $\mathrm{pH}$ 3.1. The ACE inhibitor was applied to a Dowex 50WX8 column $(32 \phi \times 840 \mathrm{~mm})$ previously equilibrated with a $0.2 \mathrm{M}$ pyridine-acetate mixture, $\mathrm{pH} 3.1$, and eluted by a linear gradient of $\mathrm{pH} 3.1$ to $\mathrm{pH} 5.0$ with the pyridine-acetate buffer. 
Active fractions were collected, evaporated to dryness and dissolved in acetate. The ACE inhibitor was applied to the second Dowex 1-X4 column $(32 \phi \times 840 \mathrm{~mm})$ and eluted with a linear gradient of 0.01 to $2 \mathrm{~N}$ acetate. However, the second Dowex 1-X4 column was not as efficient as expected. The ACE inhibitor was further purified on a silica gel column $(32 \phi \times 460 \mathrm{~mm})$, previously equilibrated with a mixture of propanol and ammonia $(7.5: 2.5)$. Active fractions were separated and retarded after high ninhydrin positive fractions. The ACE inhibitor was rechromatographed on the silica gel column. The active fractions were obtained as before. The ACE inhibitor was then gel-filtrated on the Sephadex G-25 column $(22 \phi \times 980 \mathrm{~mm})$, previously equilibrated with deionized water to separate by the differences in molecular weights. These results are not shown, but the molecular weight of the ACE inhibitor was estimated to be about 300 , judging from the authentic substance, alanine, glutathione, and oxidized glutathione. The ACE inhibitor was finally purified by high performance liquid chromatography (HPLC) on an Asahipak NH2P column as shown in Fig. 1. The ACE inhibitory activity was eluted with a linear gradient of $62 \%$ acetonitrile in water to $50 \%$ acetonitrile in $0.2 \mathrm{~N} \mathrm{NH}_{4} \mathrm{OH}$. The active fraction did not have a strong absorbance at $220 \mathrm{~nm}$. This phenomenon suggested that the molecular weight of the present ACE inhibitor has no characteristic chemical group with absorbance. The final ACE inhibitor from Morokheiya was attempted to be chemically identified. In the present study, the authors tried various purification methods, and some volume of the ACE inhibitor was lost during each purification step. Therefore, a table of the purification steps is not shown.

Identification of ACE inhibitor from Morokheiya According to the mass spectrum (Voyager MALDI-TOF/ MS, Japan Perceptive Co., Tokyo) of the ACE inhibitor after gel filtration on Sephadex G-25, two components with molecular weights of 303 and 202 were identified. Nicotianamine from tobacco leaves (Noma et al, 1971) was reported to have a molecular weight of 303 , and nicotianamine from Japanese soy sauces (Kinoshita et al., 1993) was also reported to have ACE inhibitory activity. Moreover, on the preliminary TLC, the present ACE inhibitory activity was detected on the same migration as nicotianamine. Therefore, the final preparation, obtained after HPLC, was applied to the follow- ing identification procedures with nicotianamine.

Final preparation of the ACE inhibitor after normal phase HPLC was applied to an amino acid analyzer (Yanagimoto L-7, Yanagimoto Co., Kyoto). As shown in Fig. 2, the elution profile of the ACE inhibitor was similar to that of nicotianamine. It was determined that the $\mathrm{ACE}$ inhibitor from Morokheiya was nicotianamine, but this elution time is also similar to cystine. Therefore, the following identification was made with nicotianamine and cystine.

The present ACE inhibitor was identified by TLC (silica gel $60 \mathrm{~F}_{254}$, Merck Co.) with three kinds of developing solvents. As shown in Fig. 3, in any solvent, the migration of the ACE inhibitor was coincident with nicotianamine and different from cystine. The ACE inhibitor from Morokheiya was definitely nicotianamine.

The ACE inhibitor was applied to capillary electropho-



Fig. 2. Chromatography of ACE inhibitor on amino acids analyzer. ACE inhibitor was applied to an amino acid analyzer. Elution profiles of ACE inhibitor (A) and nicotianamine (B) are shown at absorbances of $440 \mathrm{~nm}$ and $570 \mathrm{~nm}$.

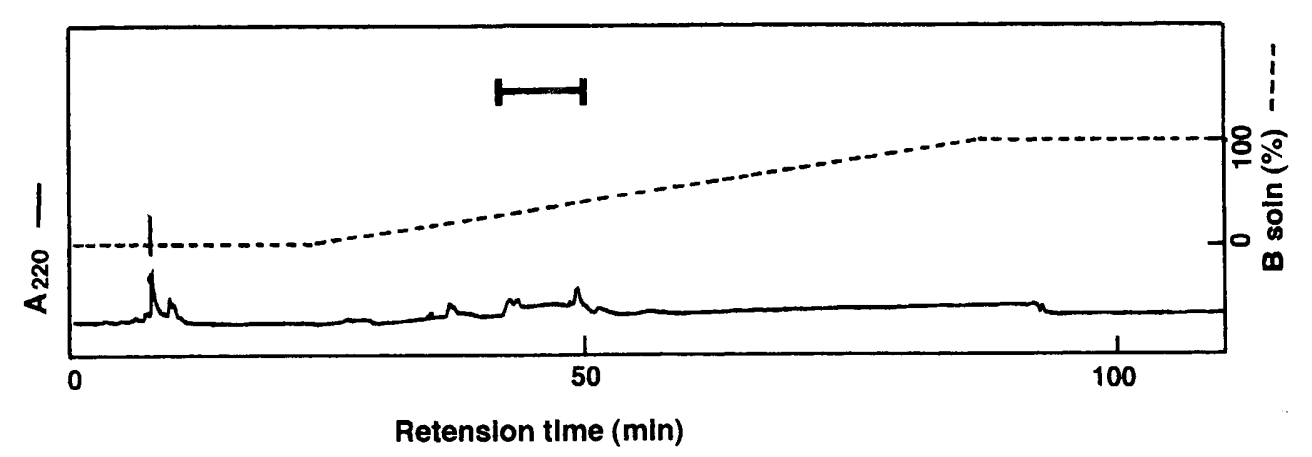

Fig. 1. Normal phase HPLC of ACE inhibitor on Asahi pack NH2P-50. Active fraction obtained after Sephadex G-25 was applied to a HPLC column previously equilibrated with $62 \%$ acetonitrile. The column was eluted with a linear gradient of aqueous $62 \%$ acetonitrile soln. to $50 \%$ acetonitrile- $0.2 \mathrm{~N}$-ammmonia mixture. The fraction was $5 \mathrm{ml}$ each. 


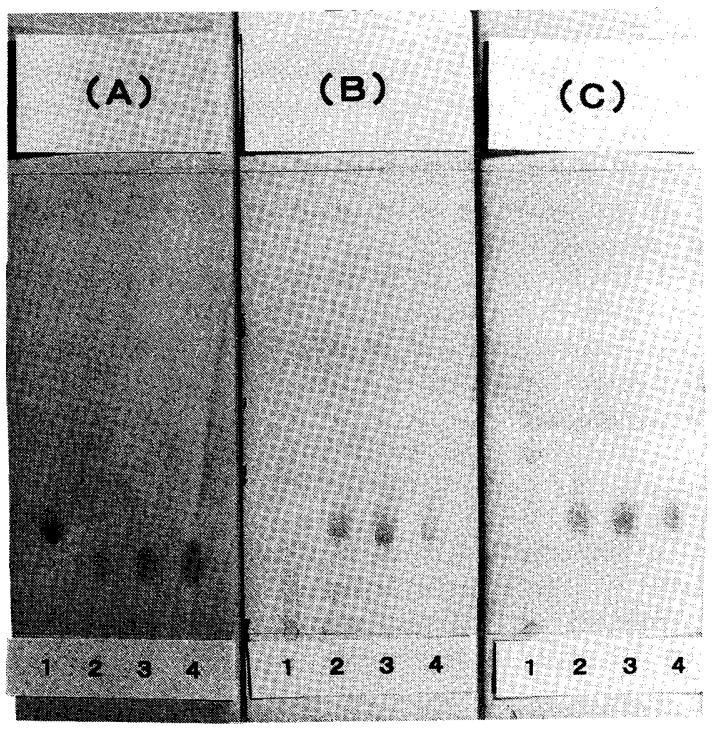

Fig. 3. Thin layer chromatography of $\mathrm{ACE}$ inhibitor on silica gel plates. Cystine (1), ACE inhibitors before (2) and after (3) HPLC and nicotianamine (4) were applied to silica gel G TLC plates and developed with three kinds of solvent, (A) $n$-propanol and ammonia (7:3), (B) $n$-propanol: pyridine: acetic acid and water (15:10:3:12) and (C) $n$-butanol: methanol: water (2:1:1). After developing the plates, the substances were detected by ninhydrin reaction.

resis (Quanta 4000E, Millipore Co., Milford, MA) at $25 \mathrm{mM}$ sodium phosphate buffer, $\mathrm{pH} 2.5$. As shown in Fig. 4, the electropherogram of the ACE inhibitor from Morokheiya was similar to that of nicotianamine. The present ACE inhibitor was then mixed with nicotianamine and the mixture was applied to capillary electrophoresis. The electropherogram indicated only one peak. These results suggested that the present ACE inhibitor was the same substance as nicotianamine.

As previously mentioned above, the ACE inhibitor from Morokheiya was identified to be nicotianamine. The nicotianamine from tobacco leaves had been first reported by Noma et al. (1971). They (Noma \& Noguchi, 1976) reported that nicotianamine had an optimal molecular structure, chelating irons, and was considered to be a possible phytosiderophore with an essential function in plant cellular iron transport and metabolism. Budesinsky et al. (1980) reported the presence of nicotianamine in Leguminosae and isolated it from the aerial parts of alfalfa (Medicago sativa L.). They suggested that nicotianamine might cause the present ACE inhibitory activity because of a powerful chelating action. Nicotianamine has been reported in some higher plants and a kind of microorganism, based on a patent application claim (Ouchi et al., 1995) in Japan. Kinoshita et al. (1993) reported the physiological and biochemical natures of nicotianamine from soy-source. Their report showed that nicotianamine had ACE inhibitory activity and depressed the blood pressure of SHR (spontaneously hypertensive rat) after a single oral injection. Many reports about ACE inhibitors have recently been published (Maruyama et al, 1987; Miyoshi et al, 1991; Matsufuji et al, 1994; Murakami et al, 1995). Most of their peptides have a $\mathrm{COOH}$-terminal dicarboxylic acid and an antepenulting aromatic amino acid residue, chelating and enhancing the binding of the ACE. Nicotianamine has

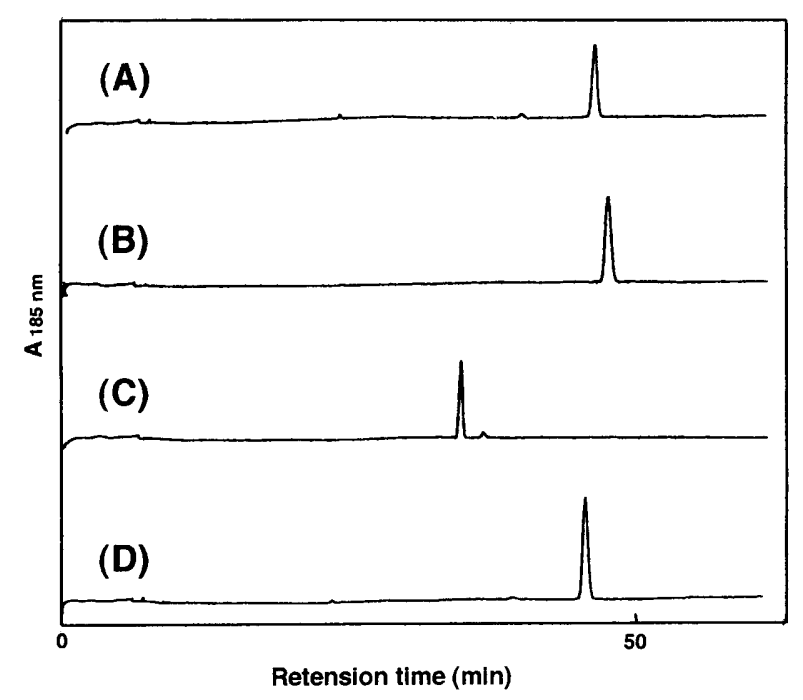

Fig. 4. Electropherograms of ACE inhibitor on capirally electrophoresis. ACE inhibitor was applied to a capillary column previously equilibrated with phosphate buffer, $\mathrm{pH} 2.5$, and electroded under the same conditions. The electropherogram of $\mathrm{ACE}$ inhibitor (A) was compared to nicotianamine (B), cystine $(C)$ and a mixture (D) of ACE inhibitor and nicotianamine.

carboxylic acids and an antipenaltinate amino acid with a ring structure.

Many studies on ACE inhibitors from food stuffs have been focused on peptide products from the hydrolysates of various protein sources. The present ACE inhibitor from Morokheiya was very characteristic due to its naturally occurring substance in Morokheiya and very different from peptide, secondary products from protein sources. We may not expect to obtain a greater volume of nicotianamine from Morokheiya than from any other protein sources. However, Morokheiya is very famous for being abundant in some nutrient components, calcium etc. Especially, dietary fiber participates in controlling cholesterol and cardiovascular disease and is speculated to have a good effect on hypertensive patients. Therefore, nicotianamine in Morokheiya may have additional effects with these authentic nutritional components for human health. The authors plan to clarify the biological and physiological systems for hypertension in vivo. There must be further investigations on the metabolism of nicotianamine after long-term administration.

Acknowledgments We thank E. Kinoshita of Kikkoman Co., Ltd., for supplying the nicotianamine. We wish to thank Mr. A. Watarai of Japan Perseptive Co., Ltd., for his kind help in the measurement of mass spectrometry. We also express our sincere thanks to Mrs. A. Hayashi, assistant at Tokyo-Kasei University, for her valuable suggestions and kind help in these experiments.

\section{References}

Budesinsky, M., Budzikiewisz, H., Prochazka, Z., Ripporger, H., Romer, A., Scholz, C. and Schreider, K. (1980). Nicotianamine, a possible phytosiderophore of general occurrence. Phytochemistry, 19, 2295-2297.

Cushman, D.W. and Cheung, H.S. (1971). Spectrophotometric assay and properties of the angiotensin-converting enzyme of rabbit lung. Biochem. Pharmacol., 20, 1648-1673.

Dzau, V.J. (1988). Circulating versus local renin-angiotensin system in 
cardiovascular homeostasis. Circulation, 77 (suppl. 1), 4-13.

Kinoshita, E., Yamazaki, J. and Kikuchi, M. (1993). Purification and identification of an angiotensin-converting enzyme inhibitor from soy source. Biosci. Biotech. Biochem., 57, 1107-1110.

Kohama, Y., Matsumoto, S., Oka, H., Teramoto, T., Okabe, M. and Mimura, T. (1988). Isolation of angiotensin converting enzyme inhibitor from tuna-muscle. Biochem. Biophys. Res. Commun., 155, 322-337.

Maruyama, S., Mitachi, H., Tanaka, H., Tomizuka, N. and Suzuki, H. (1987). Studies on the actine site and antihypertensive activity of angiotensin I-converting enzyme inhibitor derived from casein. Agric. Biol. Chem., 51, 1581-1586.

Matsufuji, H., Matsui, T., Seki, E., Osajima, K., Nakashima, M. and Osajima, Y. (1994). Angiotensin I-converting enzyme inhibitory peptides in an alkaline protease hydrolyzate derived from sardine muscles. Biosci. Biotech. Biochem., 58, 2244-2245.

Miyoshi, S., Ishikawa, H., Kaneko, T., Fukui, F., Tanaka, H. and Maruyama, S. (1991). Structure and activity of angiotensin I-converting enzyme inhibitory in an a-Zein hydrolysate. Agric. Biol.
Chem., 55, 1313-1318.

Murakami, T., Hayashi, M. and Yoshizumi, H. (1995). Lowering of the vascular wall in stroke-prone spontaneously hypertensive rats fed Euglena Diet. Jpn. Soc. Nutr. Food Sci., 48, 203-208

Murayama, S. and Suzuki, H. (1982). A peptide inhibitor of angiotensin I converting enzyme in the tryptic hydrolysate of Casein. Agric. Biol. Chem., 46, 1393-1394.

Noma, M. and Noguchi, M. (1976). Occurrence of nicotianamine in higher plants. Phytochemistry, 15, 1701-1702.

Noma, M., Noguchi, M. and Tamaki, E. (1971). New amino acid, nicotianamine, from tobacco leaves. Tetrahedron Lett., 22, 2017 2020.

Ouchi, S., Matsuhashi, Y. and Miyado, S. (1995). Production of nicotianamine by microorganism. Jpn. Tokkyo Koho, 7-40950, May 10.

Ukeda, H., Matsuda, H., Kuroda, H., Osajima, K., Matsufuji, H. and Osajima, Y. (1991). Preparation and separation of angiotensin I converting enzyme inhibitory peptide. Nippon Nogeikagaku Kaishi, 65, 1223-1228 (in Japanese). 